\title{
Government Employees of Bangladesh and their Willingness to Pay for Social Health Insurance
}

\author{
Soeb Md. Shoayeb Noman (Corresponding author) \\ Ph.D. Research Fellow, Department of Economics \\ Jahangirnagar University, Savar, Dhaka-1342, Bangladesh
}

Tel: 880-181-714-4427Ｅ-mail: shoayebnoman@gmail.com

Received: January 4, 2021 Accepted: January 30, 2021 Published: May 3, 2021

doi:10.5296/ber.v11i2.18433ＵRL: https://doi.org/10.5296/ber.v11i2.18433

\begin{abstract}
Determining the health insurance premium is the most important aspect in providing social health insurance. In measuring the rate, it is needed to calculate the cost of providing the service. One possible methodological tool of calculating the cost is the contingent valuation method for the evaluation of the consumers' capacity and their willingness to pay for the services. This study applied a Logit model, having binary depended variable with follow up dichotomous choice at different premium levels, to estimate the factors associated to joining the social health insurance scheme. The study found that 80.1 percent of the government employees of Bangladesh wants to pay on average 6.69 percent of their basic salary as social health insurance premium. The result shows that younger peoples are less willing to pay while older people are more willing to pay for social health insurance. The study also revealed that the area of residence and no of visit to doctor play a key role in determining the willingness to pay. This study should help the policymakers to formulate and implement the social health insurance scheme in Bangladesh.
\end{abstract}

Keywords: Willingness to pay, Social health insurance, Logit model, Insurance premium, Contingent valuation

\section{Introduction}

Changing the dimension of budgetary resources and the political environment ensures government policy reforms. It became obvious in many low income countries to reduce the subsidies for healthcare which stimulated health sector financing reforms. Implementation of government policies are increasing direct household financing in health care services. Health insurance, commonly and well known, is used to finance market based health care system. In current times or in near future for health care services, it may not be wise to depend only on 
government tax and out of-pocket payments of the patients. As the medical costs are increasing rapidly, to bear the increasing medical cost, there is a need for alternatives such as health insurance. It will reduce the burden of both the government and the patients by shifting the pressure from health care system of a country.

The most common and effective substitute for tax based health care financing is the social health insurance (SHI). It is needed to measure the cost required for the successful implementation of SHI, and the ability and willingness of the consumers to pay the premiums. Pricing plays a significant role in providing any kind of services and defining any policy related to it. But, it remains difficult to relate consumer's willingness or the demand of a service with the cost of the service or the price of providing it. Willingness to pay for a service is the maximum amount that the consumers will definitely pay for the goods or services. As a methodological tool, willingness to pay can be used to measure the ability of a group of consumers by offering them hypothetical monetary value for providing a specific product (Quevedo et al., 2009). Compare to cost-effectiveness analysis, WTP methods incorporated the opportunity cost more accurately and thoroughly (Quevedo et al., 2009). That's why it is very difficult to implement WTP method and interpret the responses to the questions related to health care facilities. But it is possible to use and implement WTP method when there prevails a scope to allocate resources between health care and other sectors (Hanley et al., 2003).

The constructive preference view assumes consumer willingness to pay is context-sensitive thus it depends on the concrete decision context (Hanley et al., 2003). In that sense willingness-to-pay can be used to derive the valuation of health benefits in monetary terms. Different health care system has different structures for making their purchasing choices. In many health care system for much of their care, patients make direct purchasing choices and in others they do not. Willingness to pay methods are commonly used where the pricing or the valuation of the services is very easy and straight forward. As the pricing of social health insurance is not straight forward, it is needed to make the adjustments in WTP method. The contingent valuation method is such kind of method in which individuals determine their willingness by comparing different hypothetical situations (Ryan et al., 2001). Such kind of application in WTP studies can be seen in certain health care fields (Ryan et al., 2001).

In determining willingness to pay, contingent valuation method have been used in the studies on many developing countries as well (Wright et al., 2009). Although the use of the method was first introduced by S.V Ciriacy Wantrup in 1947 and formally used and practiced by both Davis in 1963 and Randal in 1974 (Green et al., 1998). There are other uses of contingent valuation method, especially in hypothetical market situation and cost benefit analysis in health economics (Cawley et al., 2006). With a proper application, it is possible to use the method for pricing in any health studies.

\section{Literature Review}

Different studies have conducted by many authors to determine the consumers' willingness to pay for certain goods and services. Clarke and others (2018) tried to explore the connotation between attitudes and demographic factors by conducting interviews. They wanted to explore 
the reason behind consumers' decision on their willingness to pay and found high out-of-pocket payment for health care service creates disparities among consumers. Binomial Logit model of contingent valuation method has been used by Rodríguez and others (2008) to measure the willingness to pay (WTP) for five organic selected products available in the Argentinean domestic market.

Similarly, the CVM has been applied to measure the experts' WTP for mitigation and adaptation measures against the climate change (Markantonis and Bithas, 2009). The estimated WTP through CVM is expected to be utilized as useful information of the demand side (Fujita et. al., 2005). Ferna'ndez and others (2013) aimed to evaluate the perception of economic value of nursing consultation in primary care (PC) using contingent valuation method. Study revealed average area income, personal income, consultation duration, home visit, and level of education are associated with greater WTP, whereas women and older subjects showed lower WTP. The study also accepts contingent valuation is a useful method for measuring willingness to pay for health services.

There are several studies in the field of medical studies which determines the willingness to pay for medical services (Oremus, et al., 2013). To elicit individuals' preferences for healthcare services the contingent valuation method has been used by Hill, Adams and Hislop (2015). Studies have been conducted by different authors to assess the willingness to pay for health insurance as well. Basazal and others (2017) assessed willingness of the public servants to pay for National Health Insurance Fund (NHIF) with cross-sectional data using contingent valuation method. The study indicated that $68 \%$ were willing to pay varying percentages of total monthly individual income as premium for medical consultation, laboratory services and drugs.

Ahmed and others (2016) used the bidding game version of contingent valuation method to estimate weekly WTP and found that $86.7 \%$ of informal workers want to pay. Monthly income, occupation, geographical location and education were the key determinants of WTP. In order to reduce unrestricted burden due to cash constraints, Fonta and others (2011) advised for the implementation of a mechanism which ensures instalment payments over time and wealthier household may subsidize those who cannot afford to pay the onset price. Al-Hanawi and others (2018) used contingent valuation method and Tobit regression analysis to examine the willingness of the household to pay for a contributory national health insurance scheme and investigated the feasibility and acceptability of healthcare financing reform. In their analysis, they showed that a significant number of people wanted to pay for a contributory national health insurance. Several factors associated with the study were found statistically significant and plays positive role in determining WTP (Al-Hanawi et. al., 2018).

To ensure universal health coverage, Ethiopia wanted to introduce a mandatory health insurance scheme. But lack of support from public servants, the implementation of social health insurance was delayed. Gidey and others (2019) aimed to assess willingness of the public servants to pay for social health insurance and tried to find the determinants that played significant role. Using logit model they found $85.3 \%$ respondents were willing to pay $3.6 \%$ of their monthly basic salary for the scheme, and insurance premium, benefit package 
and quality of health service were the major influential factors (Gidey et. al, 2019). While investigating the willingness of households to pay for community healthcare scheme using contingent valuation method Ataguba and others (2007) found that community members were not only willing to participate with a high level of confidence but also high level of optimism yields higher amounts. In 2015, Pavel and others used contingent valuation method to estimate the willingness of the consumer to pay for specific aspects in improving the quality of the health care (Pavel, et. al, 2015).

As there exist a widespread informal sector in Tunisia, the major challenges in their health sector reform was their rising economic insecurity and inequality. In case of Tunisia, Abu-Zaineh, and others (2018) revealed that patients were willing to pay more as premium if they can get a closer doctor- patient relationship, increased available drug and increased chances of recovery. Azhar, Rahman and Arif (2018) used multi-stage cluster sampling with cross sectional study whereas Jofre-Bonet and Kamara (2018) elicited the WTP using the double-bounded dichotomous choice with follow up method. Both of them separately concludes that the WTP for the HI depends on region, occupation, level of education, gender, marital status, monthly family income and treatment preference. They also examined the factors and found that WTP is positively influenced by driving status, level of education, the number of pregnant women, having a TV, and having paid for the last medical requirement.

Using bidding game techniques and ordered probit model of willingness to prepay determinants, Binam, Nkama and Nkendah (2004) measured and found $21 \%$ respondents of Cameroon were willing to pre-pay. Khan and Ahmed (2013) applied multiple-regression analysis for predicting willingness of the informal workers in urban Bangladesh to pay for health insurance and assessed the impact of an educational intervention. They concluded that educational intervention plays a significant role on workers willingness to join health insurance.

As the culture and the behaviour of the residents of a country are different from others even for the different regions of a country, there is a need for separate study on each area to assess the willingness to pay. Thus the studies suggest that there is an opportunity and need for studying the willingness to pay and the factors associated with their decision of joining social health insurance in Bangladesh. As the government employees can truly represent, it will be worthy and also relevant to study the willingness of them to pay for social health insurance scheme and find the factors that influence their decision of joining.

\section{Methodology}

\subsection{Research Design}

Different studies have used different ways while estimating the consumers WTP for different goods and services. In yet to exist HI framework and yet not marketed, the most extensively used approach is stated preferences which is pretty much different from revealed preferences. One of the well-known stated preferences method is contingent valuation (CV), in which respondents are asked to reveal their willingness to pay for a given good or service after describing what is on offer (Nosratnejad et al., 2016). According to Nosratnejad et al., (2016), 
to draw out answers from individuals the CV method can follow three different general approaches. Using respondents' bids, asking take or leave it questions, or put on dichotomous choice methods are the three different approaches. In the first approach, after describing the hypothetical scenario, the respondents are given open-ended questions asking how much they are willing to pay for a good or service. In the second approach the individuals are presented with a series of possible alternatives from which they chose their most likely one. In the last approach, for hypothetical goods or services, the individuals are asked whether they are willing to pay a certain amount.

Lopez-Feldman (1991) and Hanemann and others (1985), described the simplest form of the double bounded dichotomous choice method, in which the individuals are asked whether they would pay a given amount to obtain specific goods and services. This study applies the above mentioned simplest form of double bounded dichotomous choice in measuring the WTP for SHI for the government employees in Bangladesh. Under the assumption of linearity, this allows expressing the WTP as a function of the individual entity's characteristics. The individuals have answered "Yes" to the question of accepting SHI scheme only if their WTP is greater than the proposed percentage of salary as premium for SHI financing. But if the individuals have answered "No", it is assumed that they are not willing to pay for the proposed percentage of salary. The normality assumption ensures that the probability of having a favorable observation to the question can be pronounced as a function of the individuals' characteristics. The respondents were also asked how much premium they want to pay in form of the percentage of their basic salary. This enables to do two types of analyses. Firstly, their willingness to pay and the mean amount of WTP for the services; and secondly, identifying the characteristics that influence the probability of accepting the SHI scheme at different premium levels. The study runs a logit model to estimate the factors associated with answering "yes" to joining the SHI scheme at different premium levels.

\subsection{Sampling Process}

This is a cross sectional study and the convenient sampling technique has been used to select the respondents. To perform a double bounded contingent valuation method, the sufficient sample size should be as low as 250 (Calia and Strazzera, 2000 and Kamara et al., 2018). According to the Ministry of Public Administration (MOPA), Government of the People's Republic of Bangladesh, the number of government employee was 1,375,438 in 2014. This study ensured that it has a sample size of at least 400 government employees from different households of Bangladesh. A structured questionnaire was developed to collect the data from different sources. The questionnaire has three (3) different sections; first, the socio-economic information of the respondent; second, respondents' disease and treatment related information; and third, social health insurance related information.

While collecting the data, at first, the participants were given explanation on the purpose of the study and current health care financing system of Bangladesh. Then the hypothetical situation was explained to the government employees and provided them the written questionnaire. After the explanation of the questionnaire and the payment methods, they were asked to fill up the questionnaire and send it back. They were assured of the data 


\section{Macrothink}

confidentiality, and informed written consent was taken from the respondents.

\subsection{Analytical Technique}

This study collected more than 400 filled up questionnaire, out of which 400 were found to be properly filled up and acceptable. Data entered and analyzed using the Statistical Package for the Social Sciences (SPSS) 22.0 version. Data has been cleaned using standard technique explained by Fichman and Cummings, (2003) and exploratory analysis was done to obtain descriptive information. After that binary logistic regression (logit) model has been used to find statistically significant variables which determines respondents' willingness to pay for social health insurance.

As binary logistic regression is simple, easy to explain and commonly used for determining the consumer's willingness to pay (Tabachnick and Fidell 2013), the study has decided to use it. To obtain parameters, the binary logistic regression estimates the following formulated theoretical model:

$$
\mathrm{WTPi}=\beta_{1}+\beta_{2} \mathrm{Ag}+\beta_{3} \mathrm{Rs}+\beta_{4} \mathrm{Fs}+\beta_{5} \mathrm{Mi}+\beta_{6} \mathrm{Md}+\beta_{7} \mathrm{Vd}
$$

Where:

$\mathrm{WTP}_{\mathrm{i}}=$ Whether $\mathrm{i}$ respondent is willing to pay premium for the social health insurance or not;

$\mathrm{Ag}=$ Age of the respondents;

Rs $=$ Residence of the respondents;

Fs = Family size of the respondents;

$\mathrm{Mi}=$ Monthly personal income of the respondents;

$\mathrm{Md}=$ Respondents have major disease; and

$\mathrm{Vd}=$ Respondents' total visit to doctor per month

Finally, the study has identified the factors which have significantly influence the willingness to pay the premium of health insurance.

\section{Data Analysis}

\subsection{Socio-demographic Characteristics}

Table 1. Percentile of gender and marital status of the respondents

\begin{tabular}{|l|l|l|l|}
\hline Gender & Percentage & Marital Status & Percentage \\
\hline Male & 69.2 & Married & 86.8 \\
\hline Female & 30.8 & Single/ Widow & 13.2 \\
\hline
\end{tabular}

Table 1 and Table 2 show the socio-demographic characteristics of the respondents in frequency with corresponding confidence interval. The mean age (SD) for the respondents 
was 39.64 (10.3) years with minimum of 21 years and maximum of 60 years old. About one-third of the respondents were female (30.8\%) and the rest were male (69.2\%). 86.8 percent were married and the rest (13.2\%) was either living single or divorced. 43.4 percent residents are from city corporation and 23.5 percent and 33.1 percent are from puro corporation and union porishod respectively.

Table 2. Socio-demographic characteristics of the respondents

\begin{tabular}{|l|l|l|l|l|}
\hline Characteristics & Percentage/Mean & Standard Deviation & Maximum & Minimum \\
\hline Age & 39.64 & 10.34 & 60 & 21 \\
\hline No of Family Members & 4.29 & 1.4 & 10 & 1 \\
\hline Monthly Personal Income & 37089.55 & 35034.90 & $1,20,000$ & 8,000 \\
\hline $\begin{array}{l}\text { Monthly Family } \\
\text { Expenditure }\end{array}$ & 36872.52 & 31989.16 & $5,00,000$ & 9,000 \\
\hline Yearly Visit to Doctor & 4.94 & 3.86 & 30 & 1 \\
\hline Monthly Medical Expense & 5075.53 & 12311 & $2,00,000$ & 0 \\
\hline
\end{tabular}

The mean (SD) family size was 4.29 (1.4) ranging from single living to 10 family members. About four-fifth $(80.4 \%)$ of the respondents had family size 3-5. The median and mean family income was BDT 45,000 \& BDT 58,764 with a maximum income of BDT 2,000,000 and a minimum income of BDT 11,000. Almost $39.7 \%$ of the respondents had major diseases while other $60.3 \%$ didn't have any major diseases.

\subsection{Willingness to Pay}

Only 19.9 percent of the respondents did not agree to pay, whereas 80.1 percent agreed to pay health insurance premium. The reasons behind this opinion is that 88.4 percent people think that social health insurance is required for improving local health standard and 60.6 percent respondents understands that government's medical allowances are not sufficient. However, $36.4 \%$ of the respondents were not willing to pay $5 \%$ of their basic salary as premium; whereas the mean premium is 6.69 percent. Interestingly, 69.72 percent government employees understand the potential benefits of social health insurance.

\subsection{Factors Affecting Willingness to Pay}

To identify potential willingness to pay predictors, the study used logit model and conducted binary logistic regression. The model was prepared in a manner that dichotomized into 'Yes' or 'No' for willingness to pay. The regression was run several times to check the potential predictors. By doing that the study tried to find out the statistically significant variables and dropped the insignificant ones from the model. The study then explored and finalized the better fitted model, and also interpreted it.

Age, residence, family size, monthly personal income, major disease and visit to doctor appeared to be potential predictors for willingness to pay for social health insurance. It has been revealed that younger people are not as much as willing to pay as the older people does for health insurance. Older peoples are two times more likely to pay the premium for social health 
insurance. Area of residence and no of visit to doctor plays a key role in determining the willingness to pay.

\section{Conclusion}

More than four-fifth of government employees of Bangladesh were willing to pay at an average of 6.69 percent of basic salary. The policy makers of Bangladesh can use it for the successful development and implementation of Social Health Insurance in Bangladesh as it provides the information of the amount that people wants to pay as a premium. On the other hand, it will increase the confidence of the Bangladeshi nationals on government for the proper implementation of social health insurance.

\section{References}

Abu-Zaineh, M., Chanel, O., \& Makhloufi, K. (2018). Accounting for Protest Attitudes in Willingness to Pay for Universal Health Coverage.

Ahmed, S., Hoque, M. E., Sarker, A. R., Sultana, M., Islam, Z., Gazi, R., \& Khan, J. A. (2016). Willingness-to-pay for community-based health insurance among informal workers in urban Bangladesh. PloS one, 11(2). https://doi.org/10.1371/journal.pone.0148211

Al-Hanawi, M. K., Vaidya, K., Alsharqi, O., \& Onwujekwe, O. (2018). Investigating the Willingness to Pay for a Contributory National Health Insurance Scheme in Saudi Arabia: A Cross-sectional Stated Preference Approach. Appl Health Econ Health Policy. https://doi.org/10.1007/s40258-017-0366-2

Ataguba, J. E., Ichoku, H. E., \& Fonta, W. M. (2007). An estimation of the willingness to pay for community healthcare insurance scheme in rural Nigeria. 6th PEP Research Network General Meeting Sheraton Lima Hotel. Paseo de la Republica 170 Lima, Peru. https://doi.org/10.2139/ssrn.1266163

Azhar, A., Rahman, M. M., \& Arif, M. T. (2018). Willingness to Pay For Health Insurance in Sarawak, Malaysia: A Contingent Valuation Method. Bangladesh Journal of Medical Science, 17(02). https://doi.org/10.3329/bjms.v17i2.35876

Basaza, R., Alier, P. K., Kirabira, P., Ogubi, D., \& Lako, R. L. L. (2017). Willingness to pay for National Health Insurance Fund among public servants in Juba City, South Sudan: a contingent evaluation. International journal for equity in health, 16(1), 158.

https://doi.org/10.1186/s12939-017-0650-7

Binam, J., Nkama, A., \& Nkenda, R. (2004). Estimating the willingness to pay for community health prepayment schemes in rural area: a case study of the use of contingent valuation surveys in centre Cameroon.

Calia, P., \& Strazzera, E. (2000). Bias and efficiency of single vs double bound models for contingent valuation studies: a Monte Carlo analysis 36). Applied Economics, 32(10), 1329-13. https://doi.org/10.1080/000368400404489

Cawley, J., Lillard, D., Mcinnes, M. M., Nicholson, S., Poe, G., Shinogle, J., \& Swanson, J. 
(2006). Contingent Valuation Analysis of Willingness to Pay to Reduce Childhood Obesity. Cambridge. https://doi.org/10.3386/w12510

Clarke, E. V., Schneider, J. L., Lynch, F., Kauffman, T. L., Leo, M. C., ... Rosales, A. G. (2018). Assessment of willingness to pay for expanded carrier screening among women and couples undergoing preconception carrier screening. PLoS ONE, 13(7), e0200139. https://doi.org/10.1371/journal.pone.0200139

Fichman, M., \& Cummings, J. M. (2003). Multiple Imputation for Missing Data: Making the Most of What you know. Organizational Research Methods, 6(3), 282-308.

https://doi.org/10.1177/1094428103255532

Fonta, W. M., Ichoku, H. E., \& Nwosu, E. (2011). Contingent Valuation in Community-Based Project Planning: The Case of Lake Bamendjim Fishery Restocking in Cameroon. AERC Research Paper 210, African Economic Research Consortium, Nairobi.

Fujita, Y., Fujii, A., Furukawa, S., \& Ogawa, T. (2005). Estimation of willingness-to-pay (WTP) for water and sanitation services through contingent valuation method (CVM): A case study in Iquitos City, The Republic of Peru. JBICI Review, 11(March), 59-87.

Gidey, M. T., Gebretekle, G. B., Hogan M., \& Fenta T. G. (2019). Willingness to pay for social health insurance and its determinants among public servants in Mekelle City, Northern Ethiopia: a mixed methods study. Cost Effectiveness and Resource Allocation, 17, 2. https://doi.org/10.1186/s12962-019-0171-x

Green, D., Jacowitz, K. E., Kahneman, D., \& McFadden, D. (1998). Referendum contingent valuation, anchoring, and willingness to pay for public goods. Resource and Energy Economics, 20(2), 85-116. https://doi.org/10.1016/S0928-7655(97)00031-6

Hanemann, M., Loomis, J., \& Kanninen, B. (1991). Statistical efficiency of double- bounded dichotomous choice contingent valuation. American Journal of Agricultural Economics, 73, 1255-63. https://doi.org/10.2307/1242453

Hanley, N., Ryan, M., \& Wright, R. (2003). Estimating the monetary value of health care: lessons from environmental economics. Health Econ, V-12, 3-16.

https://doi.org/10.1002/hec.763

Hill, S., Adams, J., \& Hislop, J. (2015). Conducting Contingent Valuation Studies in Older and Young Populations: A Rapid Review. HEG2015_02, Institute of Health \& Society, Newcastle University.

Jofre-Bonet, M., \& Kamara, J. (2018). Willingness to pay for health insurance in the informal sector of Sierra Leone. Johns Hopkins University Bloomberg School of Public Health, United States. https://doi.org/10.1371/journal.pone.0189915

Kamara, J., Jofre-Bonet, M., \& Alice, M. (2018). A Discrete Choice Experiment to elicit the Willingness to Pay for Health Insurance by the Informal Sector Workers in Sierra Leone. Department of Economics, University of London. https://doi.org/10.11648/j.hep.20180301.11 
Khan, J. A., \& Ahmed, S. (2013). Impact of educational intervention on willingness-to-pay for health insurance: A study of informal sector workers in urban Bangladesh. Health economics review, 3(1), 12. https://doi.org/10.1186/2191-1991-3-12

Mamat, M. P., Yacob, M. R., Radam, A., Abd, G., Awang, N., \& Lim, H. F. (2013). Willingness to pay for protecting natural environments in Pulau Redang Marine Park, Malaysia. African Journal of Business Management, 7(25), 2420-2426.

Markantonis, V., Kostas, \& Bithas, K. (2009). The application of the contingent valuation method in estimating the climate change mitigation and adaptation policies in Greece. An expert-based approach. Environ Dev Sustain, Springer Science+Business Media, 12(pp. 807824). https://doi.org/10.1007/s10668-009-9225-0

Martı'n-Ferna'ndez, J., del Cura-Gonza'lez, M. I., Rodrı'guez-Martı'nez, G., Ariza-Cardiel, G., Zamora, J., Gómez-Gascón, T., ... Gil-Lacruz, A. I. (2013). Economic Valuation of Health Care Services in Public Health Systems: A Study about Willingness to Pay (WTP) for Nursing Consultations. PLoS ONE, 8(4), e62840.

https://doi.org/10.1371/journal.pone.0062840

MOPA. (2014). Statistics of Civil Officers and Staff, 2014. Statistics and Research Cell, Ministry of Public Administration, Government of The People's Republic of Bangladesh.

Nosratnejad, S., Rashidian, A., \& Dror, D. M. (2016). Systematic review of willingness to pay for health insurance in low and middle income countries. PLoS ONE, 11, e0157470. https://doi.org/10.1371/journal.pone.0157470

Oremus, M., Tarride, J., Pullenayegum, E., Clayton, N., \& Raina, P. (2013). Patients' Willingness-to-Pay for an Alzheimer's disease Medication in Canada. Patient, Springer International Publishing Switzerland, 6, 161-168. https://doi.org/10.1007/s40271-013-0014-3

Pavel, M. S., Chakrabarty, S., \& Gow, J. (2015). Assessing willingness to pay for health care quality improvements. BMC health services research, 15(1), 43.

https://doi.org/10.1186/s12913-015-0678-6

Quevedo, J. F. M., Hernandez, I., Espinosa, J. G., \& Escudero G. S. (2009). The willingness-to-pay. Rev Saúde Pública, 43(2), 352-358.

https://doi.org/10.1590/S0034-89102009005000007

Rodríguez, E., Lacaze, V., \& Lupín, B. (2008). Contingent Valuation of Consumers' Willingness-to-Pay for Organic Food in Argentina. 12th Congress of the European Association of Agricultural Economists - EAAE 2008.

Ryan, M., Scott, D. A., Reeves, C., Bate, A., \& Robb, C. M. (2001). Eliciting public preferences for health care: a systematic review of techniques. Health Technol Assess, 5(5). https://doi.org/10.3310/hta5050

Steven, G. W. (2012). Using contingent valuation to estimate willingness to pay for improved water source in rural Uganda. Michigan Technological University. 


\section{Macrothink}

Business and Economic Research ISSN 2162-4860 2021, Vol. 11, No. 2

Tabachnick, B. G., \& Fidell, L. S. (2013). Using Multivariate Statistics (6th ed.). Supper Saddle River, New Jersey 07458: Pearson Education, Inc.

Takeshi, A. (1985). Qualitative Response Models. Advanced Econometrics. Oxford: Basil Blackwell.

Wright, E. G., Asfaw, A., \& Gaag, J. V. D. (2009). Willingness to Pay for Health Insurance: An Analysis of the Potential Market for New Low Cost Health Insurance Products in Namibia. SocSci Med, 69(9), 1351-1359. https://doi.org/10.1016/S9999-9994(09)20423-5

\section{Copyright Disclaimer}

Copyright for this article is retained by the author(s), with first publication rights granted to the journal.

This is an open-access article distributed under the terms and conditions of the Creative Commons Attribution license (http://creativecommons.org/licenses/by/4.0/). 